Revista Destaques Acadêmicos, Lajeado, v. 12, n. 1, 2020. ISSN 2176-3070

DOI: http://dx.doi.org/10.22410/issn.2176-3070.v12i1a2020.2162

http://www.univates.br/revistas

\title{
PLANEJAMENTO DA SUCESSÃO NAS INDÚSTRIAS FAMILIARES DE MUÇUM/RS
}

\author{
Nathalia Helena Cervo ${ }^{1}$, Gabriel Machado Braido ${ }^{2}$, Samuel Martim de Conto ${ }^{3}$
}

Resumo: O planejamento da sucessão nas indústrias familiares é uma ferramenta importante para auxiliar na transição do poder e sobrevivência da empresa no mercado. Assim, este artigo tem como objetivo verificar como os atuais gestores das indústrias familiares de Muçum/RS planejam a sucessão de seus negócios para os sucessores. A metodologia deste estudo qualitativo consistiu em entrevistas semiestruturadas com questões abertas, e participaram deste estudo sete gestores de indústrias familiares com, pelo menos, duas gerações atuantes na empresa. A pesquisa revelou que, a maioria dos gestores, embora tenha um plano para a sucessão, esta ainda é informal e não documentado, o que evidencia que o planejamento é algo adiado e não muito discutido na organização. Por fim, ficou evidenciado que, os gestores das indústrias familiares de Muçum/RS, em sua maioria, planejam a sucessão, porém o procedimento não é discutido, formalizado e nem documentado.

Palavras-chave: Indústria familiar. Planejamento de sucessão. Sucessão. Nova gestão.

\section{INTRODUÇÃO}

A sucessão familiar, em uma organização, aparenta ser algo natural e fácil de concretizar-se. Todavia, não é esta a realidade de todas as empresas que trabalham em família. Conforme o entendimento de Bornholdt (2005), é complexo delimitar o que são empresas familiares, pois, faz parte da história da humanidade, parentes somarem esforços em busca de um sustento econômico. O autor afirma, também, que nenhuma empresa resiste à uma série de conflitos

1 Bacharel em Administração pela Universidade do Vale do Taquari - Univates. nathaliahelenacervo@gmail.com

2 Doutorando em Administração (Unisinos) e Professor Assistente da Universidade do Vale do Taquari - Univates. gabrielb@univates.br

3 Doutor em Administração (Unisinos) e Professor Adjunto da Universidade do Vale do Taquari -Univates.samuelc@univates.br 
muito agressivos, como disputa de poder e falta de consideração pela cultura da empresa em geral.

No mundo, a grande maioria das empresas atuantes é familiar, chegando a representar $90 \%$ das organizações existentes, sendo que, estas se caracterizam pelo nascimento a partir de uma aspiração do seu empreendedor em arriscar-se com paixão e determinação em seu novo negócio. Estas empresas são, em sua maioria, centralizadoras e formadas por uma ou mais famílias (ADACHI, 2006). De acordo com o autor, a transição de uma organização para a próxima geração de gestores requer um planejamento e este processo não deve ser postergado ou relacionado com a morte do fundador, mas, sim, como um passo necessário para a continuidade da organização.

A sucessão familiar é um processo demorado que deve ser planejado com calma e a longo prazo, devendo o fundador se preparar para, em um futuro próximo, deixar a gestão para um herdeiro, podendo este ser seu filho, sobrinho ou outro familiar, assim como, também, pode não encontrar nos familiares alguém com o perfil e a capacitação necessária para gerir os negócios da família. Leone (2005) destaca que $70 \%$ dos negócios de família terminam após a morte de seu fundador e somente de $10 \%$ a $15 \%$ chegam à terceira geração. Por meio destes dados, constata-se a importância de um planejamento na sucessão da empresa familiar.

Neste contexto, o planejamento surge como uma ferramenta de auxílio para o gestor e seu sucessor, como uma estratégia de sobrevivência em longo prazo. Segundo Adachi (2006), cada empresa é única e possui uma cultura organizacional própria, portanto, uma sucessão bem planejada e executada, enquanto as duas partes estão dispostas a assumirem novas funções, é essencial para que não haja uma ruptura bruta nas relações internas e externas na organização.

Devido à importância dos negócios familiares na economia do município de Muçum/RS, o presente artigo busca responder a seguinte questão: como os atuais gestores das indústrias familiares de Muçum/RS planejam a sucessão de seus negócios para os próximos gestores? Para responder a esta pergunta, o estudo objetiva verificar como os atuais gestores das indústrias familiares de Muçum/RS planejam a sucessão de seus negócios para os próximos gestores.

A cidade de Muçum/RS justifica-se para a realização deste estudo, pois é um dos municípios integrantes do Vale do Taquari, com 4.791 habitantes (IBGE, 2010) e sua economia é composta por indústrias (representando 60\%), agricultura (20\%) e comércio e serviços ( $20 \%$ ). De acordo com relatórios obtidos na Prefeitura Municipal de Muçum, há 61 indústrias em funcionamento na cidade, já o Vale do Taquari é composto por 36 municípios em sua totalidade, onde a maior parte da população dedica-se à agricultura, pecuária e micro e pequenas indústrias, reforçando a tradição de empresas familiares. 


\section{REVISÃO DE LITERATURA}

\subsection{A empresa familiar}

Bornholdt (2005) considera que uma empresa é de cunho familiar quando apresenta uma ou mais das seguintes características: a) O controle das ações é de uma família e/ou a seus herdeiros; b) A hereditariedade determina a sucessão; c) Os parentes ocupam cargos como diretoria ou conselho de administração; d) Os valores da organização e da família se identificam; e) O comportamento dos membros da família influenciam na imagem da organização (mesmo que nela não atuem); e f) Não há muita liberdade na decisão de vender ou não a parte herdada ou quotas da organização.

Oliveira (2006, p. 3) define a empresa familiar de forma simples e direita "[...] caracteriza-se pela sucessão do poder decisório de maneira hereditária a partir de uma ou mais famílias". O autor também destaca que as empresas familiares não são todas iguais, a cultura do país influencia fortemente na forma como cada empresa funciona. O Brasil, por exemplo, é paternalista e protecionista, o que ajuda a consolidar estas características nas empresas familiares constituídas no país. No mesmo contexto, Oliveira (2006) destaca a diferença entre as figuras do empreendedor e do empresário, onde o empreendedor é aquele que sonha com um novo negócio e dá início às atividades, dando origem à empresa familiar; já o empresário vai consolidar e dar continuidade à sua existência.

\subsubsection{Desenvolvimento da empresa familiar}

Dalla Costa (2007) afirma que o ciclo de vida da empresa familiar é similar das demais empresas, o que difere é que, o desenvolvimento organizacional ocorre, juntamente, com o crescimento das relações familiares. De acordo com Oliveira (2006), o ciclo de vida médio de uma empresa não familiar é de 12 anos, e das familiares de 9 anos, sendo que, uma pequena parcela sobrevive na segunda geração. $\mathrm{O}$ autor ainda apresenta que, dentre os países industrializados, $75 \%$ das empresas são familiares. Para melhor compreender essa relação entre a família e a empresa, Gersick et al. apud Dalla Costa (2007) propuseram o modelo de Três Círculos (FIGURA 1), o qual tem sido citado por diversos autores (DALLA COSTA, 2007; TONDO 2008; BORNHOLDT, 2005). 
Figura 1 - Modelo de três círculos

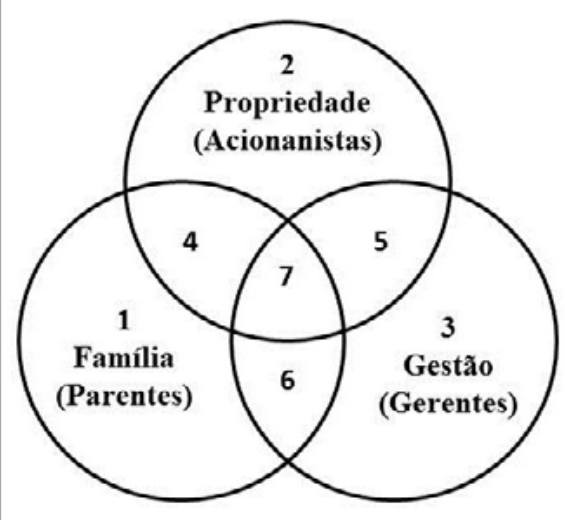

1) Familiares sem participação nos outros subsistemas.

2) Sócios-proprietários não-gestores e não-familiares.

3) Gestores não-proprietários e não-familiares

4) Familiares proprietários e sem participação na gestão.

5) Proprietários gestores não-familiares

6) Gestores familiares não-proprietários

7) Familiares gestores e proprietários

Fonte: Adaptado de Dalla Costa (2007).

O modelo dos três círculos descreve a relação entre as três grandes partes que envolvem a empresa familiar: o capital/ propriedade, família e a empresa. Os círculos representam sistemas independentes, porém sobrepostos, onde cada integrante da família pode ocupar uma posição destas sete e, ao longo do tempo, mudar de posição. De acordo com o autor do modelo tridimensional, Gersick (apud DALLA COSTA, 2007, p. 28), a "[...] razão pelo qual o modelo de três círculos teve ampla aceitação é que ele é teoricamente elegante e também imediatamente aplicável". Dalla Costa (2007) explica que, se bem observar-se o modelo exposto na Figura 1 e suas sete posições, torna-se mais fácil visualizar a empresa familiar e compreender os subsistemas e as relações existentes.

As sete posições são descritas por Dalla Costa (2007), conforme apresentado na Figura 1, nas quais, as posições 1 e 7, são os extremos. De acordo com Tondo (2008), a posição 1, na maioria das vezes, é ocupada por alguém que nasce na família empresária ou se casa (?) com um deles, e essa pessoa não participa da propriedade nem trabalha na empresa, apenas compartilha, eventualmente, de confraternizações. Já a posição 7, no centro da Figura 1, ocupando uma parte dos três círculos, é a posição mais delicada e importante dentro da organização. É esta pessoa que é dona, familiar e gestora.

É possível resumir as posições dos círculos como, os integrantes da posição 1, 2 e 3 , sendo pessoas com somente uma conexão com a empresa, os integrantes da posição 4,5 e 6 como pessoas com duas conexões, e os integrantes da posição 7, pessoas com três conexões. Como citado anteriormente, com o passar dos anos, as pessoas mudam de posição dentro dos círculos. Um familiar 
sem participação pode vir a se tornar um dos gestores ou proprietários, e assim por diante, dando continuidade à empresa.

\subsection{Estágios de desenvolvimento da empresa}

Ainda no contexto do Modelo dos três círculos, Gersick et al. apud Dalla Costa (2007), descrevem a dimensão do desenvolvimento da empresa familiar e as classificam em estágios para a propriedade, para a família e para a empresa, apresentados na Figura 2, e relatados nos tópicos seguintes.

Figura 2 - Modelo tridimensional de desenvolvimento dividido em estágios

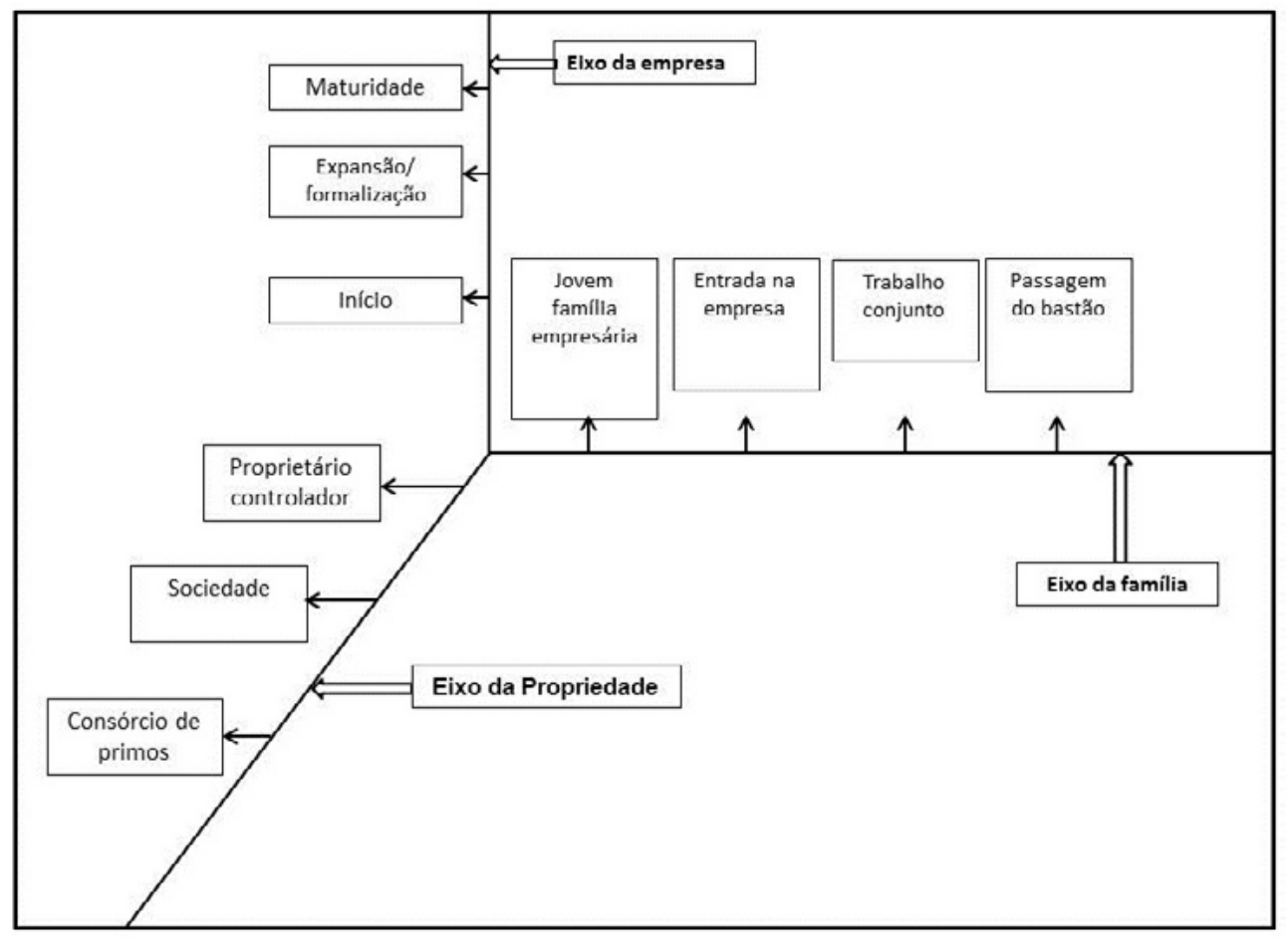

Fonte: Gersick et al. apud Dalla Costa (2007).

\subsubsection{Estágios de desenvolvimento da propriedade}

Na Figura 2, aparecem os estágios dos três círculos dispostos em eixos. No eixo da propriedade, Gersick et al. apud Dalla Costa (2007) classificam os estágios em: empresas com Proprietário Controlador; Sociedade entre irmãos e Consórcio de primos. Os autores destacam que esta é apenas uma dentre as diversas possibilidades, e que não ocorre, por regra, desta forma em todas as organizações familiares. 
O Proprietário Controlador é a empresa de um dono só e/ou mais um cônjuge, o qual não tem poder de decisão. Em casos onde há sócios, na maioria das vezes, é apenas simbólico e sem autoridade, pois, nestas empresas, é o fundador quem realiza quase todas as atividades da parte administrativa e operacional, não existindo um planejamento formal das funções internas.

A Sociedade entre irmãos, segundo Dalla Costa (2007), caracteriza-se por controle compartilhado por irmãos, às vezes, inativos na empresa. Neste estágio, os principais desafios são definir os papéis dos irmãos, reter o capital e controlar o desenvolvimento dos ramos familiares.

No Consórcio de primos, o controle está nas mãos de vários primos da família. Dalla Costa (2007) ressalta que, nenhum deles, tem sozinho o poder de decisão. A empresa familiar, quando chega neste estágio, que leva em média três gerações, possui, aproximadamente, dez ou mais proprietários.

\subsubsection{Estágio de desenvolvimento da empresa}

No eixo da empresa observam-se três estágios (FIGURA 2). O primeiro, o Início, contempla a fundação e os primeiros anos de funcionamento da empresa, onde a sobrevivência, está em questão a todo o momento. No estágio seguinte, a Expansão/formalização, Dalla Costa (2007) explica que esta fase pode durar poucos ou muitos anos, podendo ultrapassar uma geração. É onde a empresa vai se estabilizar no mercado e se expandir, criando operações rotineiras e fazendo previsões de crescimento. Este período compreende até o momento em que as mudanças organizacionais e o crescimento reduzem drasticamente. Para Adachi (2006), esta é a etapa mais árdua para o fundador, pois é dele que parte a força, a criatividade e o espírito empreendedor, lutando para expandir os negócios.

O terceiro estágio, o da Maturidade, o produto já não é mais a novidade do mercado e a empresa já não evolui como antes, isso leva à diminuição dos lucros, e o início da luta para participar do mercado. Dalla Costa (2007) afirma que, para empresas familiares neste estágio, só há dois caminhos: a reciclagem e renovação ou a falência. Para Adachi (2006), há mais um estágio após a maturidade, o declínio, que é o último passo antes do encerramento das atividades. Aqui, a empresa perde agilidade e criatividade, devido ao excesso de burocracia; dissolve-se o foco estratégico e a empresa é atropelada pelos concorrentes. O autor, assim como Dalla Costa (2007), afirma que, somente a revitalização e a inovação, são capazes de mudar este rumo.

\subsubsection{Estágio de desenvolvimento da família}

O eixo da família possui quatro estágios e, de acordo com Dalla Costa (2007), este eixo abrange todos os tipos de relações familiares: paternidade, casamentos, relacionamentos entre sogros, irmãos, primos e agregados à família. Os estágios descritos pelo autor são os seguintes: 
No estágio da Jovem família empresária, a fase é de maior intensidade no desenvolvimento da empresa, é onde formam-se parcerias conjugais que possam aguentar o papel de proprietário e gestor; também surgem questões como: ter filhos ou não, entre outras. Nesta questão, das parcerias conjugais na fase inicial da vida empresarial, Kets de Vries (1996) apud Tondo (2008) destaca que, muitos casais acabam se dedicando ao extremo no negócio, e acabam deixando de participar da vida familiar com os filhos, gerando sentimento de culpa a longo prazo e, para suprir este sentimento, muitos executivos acabam permitindo que familiares ultrapassem dos limites apropriados para o meio empresarial.

No estágio seguinte, entrada na empresa, há mais de duas gerações se relacionando profissionalmente. A diferença média de idade é de 10 a 15 anos em relação ao estágio anterior. De acordo com Dalla Costa (2007), nesta fase, as famílias preocupam-se com a construção de uma carreira para os jovens adultos, o controle de entrada de novos membros e a definição de uma atividade, de um papel dentro da empresa para cada uma das três gerações envolvidas: pais mais velhos e filhos em preparação e formando suas famílias.

No terceiro estágio, chamado de Trabalho em conjunto, os pais estão entrando na faixa dos 50 anos, e os mais jovens estão com 20 a 30 anos. Nesta fase, almejam conduzir da melhor forma possível as relações entre os parentes (pais, irmãos, primos, cunhados, sogros, crianças). Conforme Tondo (2008), esta é a fase mais extensa da vida da empresa, onde o desafio do gestor é administrar as relações familiares. Nesta fase, é possível identificar se a qualificação profissional dos familiares está de acordo e compatível com a da empresa, caso não seja, faz-se necessário um debate entre as partes.

Para Bornholdt (2005), a combinação mais eficaz para dirigir a empresa familiar é nesta fase, pois é uma mistura entre o velho e o novo. Essa heterogeneidade de idades, experiências, formação e sexo, geram muitos debates na hora da tomada de decisão, porém, a presença dos executivos mais maduros, é essencial para manter a identidade da empresa e amenizar a ansiedade interna.

No último estágio, a Passagem do bastão, é onde ocorre a sucessão de fato. Nesta fase, todos estão preocupados com a transição, por isso, este processo costuma gerar conflitos familiares e disputas internas. Dalla Costa (2007) afirma que, este fato é inevitável e, mais cedo ou mais tarde, os papéis mudam e o ciclo se inicia novamente. Mamede e Mamede (2015) explicam que é preciso que, todos os familiares envolvidos nesta fase do processo, percebam que a empresa é um patrimônio da família, devendo ser preservado e desenvolvido para continuar a oferecer resultados. 


\subsection{A sucessão na empresa familiar}

A sucessão familiar é uma temática complexa que abrange diversos paradigmas, pois não envolve somente a empresa, mas sim relações familiares, sentimentos de frustração, medo e ansiedade, entre tantos outros problemas e dúvidas inerentes à empresa familiar. $\mathrm{O}$ assunto, na maioria das vezes, é adiado pelos gestores, por associarem a ideia de sucessão à morte de algum familiar e não ao planejamento a longo prazo para a sobrevivência da empresa (ADACHI, 2006).

Leone (2005) considera que, no Brasil, o empresário, em geral, não planeja a sucessão, esquecendo-se que sua gestão não será eterna, e esta falha de planejamento abre espaço para conflitos familiares. $\mathrm{O}$ autor afirma que este duelo já nasce com a empresa e fica adormecido, sendo que, quando chega o momento no qual precisa deixar a gestão, o empresário percebe o problema. O estudioso ainda destaca que, o processo de sucessão é indispensável para a sobrevivência da empresa no mercado, e deve iniciar-se com antecedência, a fim de evitar conflitos e preservar tanto a empresa quanto a família.

As empresas, assim como as pessoas que as compõem, possuem um ciclo de vida: elas nascem, crescem e morrem. A fim de que a organização perpetue, surge a sucessão, onde as lideranças serão substituídas, revitalizando a empresa. Na empresa familiar isto também acontece. Tondo (2008 p. 85) define a sucessão familiar como "[...] transferência de poder nas decisões empresariais, de conhecimento e conclui-se com a transferência de patrimônio entre gerações". O processo da passagem do bastão não é algo que é decidido do dia para noite. Leone (2005) explica que, as bases de uma sucessão tranquila, são o planejamento e a organização, onde o sucedido prepara-se tanto quanto o sucessor, sempre deixando o restante da família a par da situação e de como o fundador está definindo a escolha de seu substituto.

Oliveira (2006) afirma que, é preciso realizar uma análise real do processo de sucessão, visto que, muitas vezes, o fundador força a situação, não reconhecendo que seus herdeiros não são os melhores gestores para sua empresa. Neste contexto, o autor identifica dois tipos de processo de sucessão: a sucessão familiar e a sucessão profissional. Dentro da sucessão familiar, há alguns aspectos que devem ser observados, são eles: a) Características da família (valores, comportamentos pessoais, atitudes, relacionamentos); b) Se valorizam mais o poder e a riqueza do que as relações familiares; c) Se há separação entre a empresa e a família; d) Qual a forma de tratamento com os parentes e agregados da família (genro, noras); e) Expectativa de vida dos familiares mais influentes; e f) O papel do patriarca e da matriarca da família.

Oliveira (2006) também classifica os herdeiros em dois tipos: os com maior envolvimento e contribuição para os negócios; e os menos dedicados. Essa classificação está a cargo do fundador da empresa, pois ela busca escalonar, de forma objetiva, quem é quem na organização e na família. Para 
Tondo (2008), a preparação do herdeiro acontece nas pequenas atividades que o fundador delega, como liderar um grupo menor de pessoas e responsabilizarse por alguns processos.

De acordo com Leone (2005), o problema da sucessão atinge um maior número de empresas pequenas e médias, onde a transição do poder e do capital ocorrem simultaneamente. Já nas empresas de grande porte, este processo é mais fácil, uma vez que já possuem seu capital no mercado financeiro e há um maior número de executivos contratados.

Oliveira (2006) defende que a questão da sucessão deve ser pensada desde o nascimento dos filhos, evitando choques sucessórios. Assim, a análise do herdeiro e sua vocação profissional serão realizadas desde cedo e de forma gradativa, possibilitando a identificação de um sucessor.

\subsubsection{Planejamento do processo de sucessão}

O processo de sucessão não é uma ferramenta pronta a ser aplicada em toda empresa, pois existem alguns passos para melhor orientar esta transição. Porém, cada situação exige determinadas competências do sucedido e do sucessor. Tondo (2008) explica que é difícil para o fundador imaginar-se fora da empresa a qual ele deu vida e a fez crescer; para os funcionários de longa data, esta aceitação da nova gerência também é difícil. No processo de sucessão, o fundador torna-se o professor do novo gestor.

Este processo deve ser conduzido pelo fundador da empresa, justamente, por exigir conhecimento pleno de todo o histórico empresarial e familiar. Adachi (2006) afirma que, o processo de sucessão, é de responsabilidade do fundador da empresa, portanto, ele deve inicia-lo, conduzi-lo e concluí-lo. O autor ressalta que, para que não haja influência emocional por parte do fundador na questão da lealdade, amizade e valores, é necessário que os funcionários da primeira geração participem da seleção de critérios para o novo cargo; essa participação gera um maior fluxo de conhecimento para o sucessor.

Bornholdt (2005) também destaca alguns pontos que devem ser avaliados pelo fundador antes de iniciar a sucessão, são eles: qual o nível de complexidade da organização, tamanho, sintonia nas relações familiares e estrutura familiar, número de herdeiros, personalidade dos candidatos a sucessor e do sucedido, quotas de ações, alianças, controle do capital, em qual fase vai ocorrer a sucessão (primeira para a segunda geração ou dessa para a terceira), se o modelo atual da gestão é bem-sucedido ou está fracassando, e órgãos adicionais, como o conselho de administração, fiscal, entre outros.

\subsection{Preparação do sucessor}

Para assumir a direção de uma empresa familiar, ser herdeiro não é o suficiente. O sucessor precisa estar munido de conhecimento técnico e experiência, ter pleno conhecimento sobre a história da organização e do legado 
construído até o momento pelo sucedido. Oliveira (2006, p. 5) afirma que o "[...] desenvolvimento da empresa familiar é um assunto de elevada importância para o futuro da economia do país; e os herdeiros e futuros executivos responsáveis por essas empresas devem ser adequadamente treinados".

Tondo (2008) recomenda para herdeiros de negócios familiares que, o desenvolvimento seja dividido em três níveis: básico, intermediário e avançado. No nível básico, a família definirá os assuntos referentes às quatro áreas que o sucessor deverá ter um conhecimento prévio, são elas: finanças, recursos humanos, comunicação e processo produtivo. No nível intermediário, o candidato a sucessor precisa validar suas aptidões de liderança através da coordenação de projetos dentro da empresa. Cabe ao gestor avaliar qual atividade o sucessor vai desenvolver. No nível avançado, Lansberg apud Tondo (2008) recomenda que seja criado um Comitê de Sucessão ou Comitê de Planejamento de Carreiras. Estes comitês, normalmente, são compostos por pessoas da família que atuem na empresa, e por profissionais atuantes na área de gestão familiar. O processo de acompanhamento e avaliação dos possíveis sucessores caberá a este Comitê.

Para o nível avançado, Tondo (2008) recomenda ainda que, os sucessores realizem cursos de extensão fora da empresa, de preferência em locais onde não sejam conhecidos pela sua posição social e profissional, visto que, estar em um local onde o sucessor e sua família não são conhecidos, propicia experiências desafiadoras e crescimento pessoal e profissional.

Dalla Costa (2007) atenta para o cuidado que o sucessor deve ter ao gerir a empresa. Ele não deve tentar ser exatamente como seu sucedido foi, ao mesmo tempo em que não deve tentar demonstrar ter uma visão melhor e modificar tudo o que vinha sendo feito. O sucessor deve se ater a manter a sequência do negócio, preservando o que é bom e reinventando o resto.

\section{PROCEDIMENTOS METODOLÓGICOS}

Esta pesquisa é de abordagem qualitativa, pois buscou verificar como os atuais gestores das indústrias familiares de Muçum/RS planejam a sucessão de seus negócios para os sucessores. Para Bell (2008), os pesquisadores que utilizam esta abordagem estão mais empenhados em compreender o que os indivíduos pesquisados entendem do mundo.

Creswell (2010) explica que, o levantamento de dados na pesquisa de abordagem qualitativa, geralmente, ocorre no ambiente do entrevistado, e a análise deste material é elaborada a partir das particularidades do tema, de acordo com a perspectiva do pesquisador; isto torna a pesquisa flexível, com uma importância mais individual.

A pesquisa classifica-se como exploratória, em razão de que buscou verificar se há ou não um planejamento sucessório nas indústrias de Muçum/ RS e de que forma ele ocorre. De acordo com Gil (1996), este tipo de pesquisa 
busca aprofundar conhecimentos acerca do problema, tendo em vista, deixalo mais claro; por estes motivos, caracteriza-se em ser uma pesquisa muito flexível. Oliveira (1997) descreve que, a pesquisa exploratória permite explanar sobre determinada hipótese e analisar suas variáveis, compreender grupos sociais, interpretar determinados comportamentos e contribuir no processo de mudança.

Quanto aos procedimentos técnicos, foi utilizada uma pesquisa bibliográfica, visando a ampliação de conhecimentos acerca do tema através de obras científicas. Além disso, também foi utilizada a entrevista semiestruturada, composta por um roteiro de 10 questões abertas, elaborado conforme Quadro 4.

Quadro 4-Questões para a entrevista

\begin{tabular}{|l|l|}
\hline Questão & Embasamento teórico \\
\hline $\begin{array}{l}\text { 1) Há um planejamento de sucessão da direção da } \\
\text { empresa? Se sim, ele é formalizado? }\end{array}$ & Leone (2005) \\
\hline $\begin{array}{l}\text { 2) Quais as principais características profissionais e } \\
\text { competências que o sucessor deve apresentar? }\end{array}$ & $\begin{array}{l}\text { Oliveira (2006) } \\
\text { Tondo (2008) }\end{array}$ \\
\hline $\begin{array}{l}\text { 3) O desenvolvimento da empresa, das relações } \\
\text { familiares e da propriedade andam juntos ou há } \\
\text { conflitos em algum destes pontos? }\end{array}$ & $\begin{array}{l}\text { Gersick et al. apud Dalla Costa } \\
(2007)\end{array}$ \\
\hline $\begin{array}{l}\text { 4) Há uma visão de um futuro sucessor e várias } \\
\text { gerações envolvidas na empresa? }\end{array}$ & Tondo (2008) \\
\hline $\begin{array}{l}\text { 5) Há perspectiva de crescimento da empresa com } \\
\text { essa nova gestão futura? }\end{array}$ & $\begin{array}{l}\text { Leone (2005) e Oliveira (2006) } \\
\text { Tondo (2008), Bornholdt (2005) } \\
\text { Adachi (2006) }\end{array}$ \\
\hline $\begin{array}{l}\text { 6) Há alguma preparação para os possíveis futuros } \\
\text { gestores? }\end{array}$ & Oliveira (2006) e Tondo (2008) \\
\hline $\begin{array}{l}\text { 7) Há um planejamento a longo prazo para o futuro } \\
\text { gestor? }\end{array}$ & Oliveira (2006) \\
\hline $\begin{array}{l}\text { 8) Este futuro gestor já tem conhecimento de que } \\
\text { será ele e está se preparando de forma adequada } \\
\text { para o cargo? }\end{array}$ & $\begin{array}{l}\text { Oliveira (2006) e Tondo (2008) } \\
\text { Bornholdt (2005) }\end{array}$ \\
\hline $\begin{array}{l}\text { 9) Os demais funcionários da organização já sabem } \\
\text { do planejamento de sucessão e possuem uma } \\
\text { receptividade para com o futuro gestor? }\end{array}$ & Adachi (2006) \\
\hline $\begin{array}{l}\text { 10) Este futuro gestor tem características de } \\
\text { liderança? }\end{array}$ & $\begin{array}{l}\text { Oliveira (2006), Tondo (2008) e } \\
\text { Bornholdt (2005) }\end{array}$ \\
\hline
\end{tabular}

Fonte: Elaborado pelos autores.

A coleta de dados se deu através de entrevistas semiestruturadas, nas quais foram apresentadas uma introdução sobre o tema, os objetivos da pesquisa e do pesquisador. $\mathrm{O}$ roteiro foi composto por perguntas abertas, 
com espaço para possíveis questões que surgiram no momento da entrevista. Sampieri, Collado e Lucio (2013) explica que, este tipo de coleta de dados é muito utilizado no estudo de fenômenos, cujos não são possíveis de observálos por sua abrangência, ou por questões de confidencialidade.

Creswell (2010) orienta para que a coleta de dados seja realizada no ambiente do entrevistado, pois é aonde se vivencia o problema em questão. Desta forma, é possível a observação face a face. O autor também frisa a importância da questão ética: no estudo de um tópico delicado, é preciso omitir os nomes.

Foram utilizadas algumas variáveis para selecionar as empresas participantes, sendo: porte da empresa conforme número de funcionários, que fossem do ramo industrial e que houvesse, pelo menos, duas gerações atuantes. Pretendia-se entrevistar 10 gestores de empresas familiares de diferentes ramos da indústria, porém, como o convite de participação não foi aceito por todos, foram realizadas sete entrevistas, conforme a disponibilidade dos entrevistados.

A análise dos dados da pesquisa foi através da análise de conteúdo. Bardin (2011) explica que, a análise de conteúdo não apresenta uma fórmula pronta para aplicação, é um método baseado em experiências e observação, a qual depende do tipo de fala e de interpretação que se tem como objetivo. De acordo com a autora, em um primeiro momento, classifica-se o conteúdo quanto a dois critérios: quantidade de pessoas envolvidas e natureza da mensagem.

Bardin (2011) sugere que, o conteúdo de cada entrevista, seja organizado e divido em sequências, e estas partes de textos sejam interpretadas e relacionadas com temas dominantes. Antes de analisar cada fragmento do texto e interpretá-lo, deve ser realizada uma análise sobre o significado geral da ideia do entrevistado. A autora explica que, esta pré-análise, permite a criação de hipóteses emergentes. Durante a análise de conteúdo de uma pesquisa qualitativa, encontra-se uma riqueza de informações muito específicas, portanto, inferir algo de forma geral, quantificando as entrevistas, acaba por esconder parte destes detalhes.

Após gravadas e transcritas, as respostas dos entrevistados foram organizadas em um quadro onde cada questão respondida formou uma categoria, apresentada em colunas ordenadas na vertical e, cada um dos respondentes, em linhas na horizontal, identificados como E1 referindo-se ao entrevistado 1 e, assim, respectivamente, até E7. Desta forma, foi possível efetuar cruzamentos de informações, identificando semelhanças ou particularidades de cada empresa, buscando responder ao objetivo da pesquisa.

A pesquisa apresenta como limitação o fato de que não é possível generalizar os resultados obtidos, visto que, estes são válidos somente para as empresas analisadas. 


\section{APRESENTAÇÃO E ANÁLISE DOS RESULTADOS}

\subsection{Caracterização das empresas}

Foram entrevistados 7 gestores de empresas familiares, das quais E1, E2 e E3 estão classificadas como Microempresa; E5, E6 e E7 estão classificadas como Empresa de Pequeno Porte, e E4 como Empresa de Médio Porte (EMP), conforme o número de funcionários, não incluindo a direção. Duas das empresas participantes já estão na $2^{a}$ geração, onde o fundador da organização não mais trabalha na empresa, portanto, entrevistou-se o atual gestor e não o fundador, como era o objetivo inicial. São elas: E3 e E6, que são, também, as duas empresas com maior tempo de existência, com 45 e 78 anos, respectivamente. Os dados de caracterização estão apresentados no Quadro 5.

Quadro 5 - Características gerais das empresas participantes

\begin{tabular}{|c|c|c|c|c|c|}
\hline Empresa & $\begin{array}{c}\mathbf{N}^{\circ} \text { de } \\
\text { funcionários }\end{array}$ & Classificação & Ramo de atuação & Geração & Existência \\
\hline E1 & 3 & ME & Alimentício & $1^{\mathrm{a}}$ e $2^{\mathrm{a}}$ & 8 anos \\
\hline E2 & 7 & $\mathrm{ME}$ & Alimentício & $1^{\mathrm{a}}$ e $2^{\mathrm{a}}$ & 27 anos \\
\hline E3 & 6 & $\mathrm{ME}$ & $\begin{array}{c}\text { Material de } \\
\text { construção }\end{array}$ & $2^{\mathrm{a}}$ e $3^{\mathrm{a}}$ & 45 anos \\
\hline E4 & 178 & EMP & Moveleiro & $1^{\mathrm{a}}$ e $2^{\mathrm{a}}$ & 37 anos \\
\hline E5 & 23 & EPP & Metalúrgico & $1^{\mathrm{a}}$ e $2^{\mathrm{a}}$ & 23 anos \\
\hline E6 & 80 & EPP & Moveleiro & $2^{\mathrm{a}}$ e $3^{\mathrm{a}}$ & 78 anos \\
\hline E7 & 50 & EPP & Calçados & $1^{\mathrm{a}}$ e $2^{\mathrm{a}}$ & 29 anos \\
\hline
\end{tabular}

Fonte: Elaborado pelos autores.

\subsection{Planejando a sucessão}

Sobre a existência de um planejamento de sucessão e se este é formalizado, os entrevistados da E1, E2 e E7 dizem ter um planejamento, porém não formalizado, onde já está definido o sucessor da direção. Os entrevistados da E4 e E6 afirmam ter um planejamento formalizado em partes, e sucessores definidos. O E3 afirma não ter um planejamento, porém teria um sucessor prédefinido e E5 não tem um planejamento de sucessão, mas afirma preocuparse com a questão. Estas informações vão ao encontro da afirmação de Leone (2005), onde o autor explica que, o empresário brasileiro, em geral, não planeja a sucessão, esquecendo-se que sua gestão não será eterna, destacando ainda que, o processo de sucessão é indispensável para a sobrevivência da empresa no mercado, e deve iniciar-se com antecedência a fim de evitar conflitos. 
Quando questionados sobre as principais características profissionais e competências que o sucessor deve apresentar, os entrevistados citaram diversas características voltadas à personalidade, ao comportamento e à capacidade de liderar e aprender. Tondo (2008) explica que, cabe aos sucessores, demonstrar conhecimento e habilidades para que, ao longo dos anos, recebam o reconhecimento como profissionais competentes por parte dos funcionários mais antigos. A autora ainda declara que, a preparação do herdeiro acontece nas pequenas atividades delegadas pelo sucedido, como liderar um grupo menor de pessoas e responsabilizar-se por alguns processos.

\subsection{Desenvolvimento da empresa e das relações familiares}

Em relação ao desenvolvimento da empresa, das relações familiares e da propriedade, os gestores afirmaram não existir conflitos nestes três eixos, com exceção do entrevistado da E1, que disse terem ocorrido conflitos entre o fundador e o sucessor em sua entrada na empresa, por falta de uma comunicação clara entre as partes. O fundador também explicou que, esta dificuldade, se deu por ele mesmo não saber ensinar o sucessor, conforme relato de E1 transcrito na sequência:

[...] hoje estamos bem mais calmas, nós trabalhamos e conversamos sobre tudo, antes eu não falava nada e segurava tudo pra mim, depois eu pensava 'Mas por que ela não fez isso? Por que não fez aquilo?' E eu mesma percebi, que eu não havia falado, não havia explicado, como ela iria adivinhar o que era pra fazer?

Todos os respondentes afirmaram que há muito debate na tomada de decisão entre o sucedido e o sucessor, onde as ideias são expostas por ambos de forma clara para que não haja conflitos posteriores. O relato de $\mathrm{E} 4$ estimula a autonomia na tomada de decisão dos sucessores, onde o fundador abre espaço para que eles tomem a decisão, afirmando que esta foi a forma mais eficaz de aprendizagem para a sua empresa, conforme descrito a seguir:

Não quero que eles aceitem tudo que eu faço, quero que eles tenham seu ponto de vista, [...] tem que ter sua própria forma de administrar... Como eles já têm a própria área deles, eu cobro resultado, eu deixo eles errarem, hoje eu vejo como se eles estivessem na fase de aprendiz, se eles errarem hoje é ótimo pra mim, pois posso corrigir.

Através do modelo tridimensional proposto por Gersik et al. (1989) apud Dalla Costa (2007), apresentado na Figura 2, pode-se classificar o estágio onde as empresas analisadas neste estudo se encontram. Identificou-se que todas as empresas estão no eixo do desenvolvimento familiar, especificamente na transição do estágio 2 para o 3, que são, respectivamente, a Entrada na empresa e o Trabalho em conjunto, com exceção da E4 e da E6, que estão com o estágio 
3 quase concluído, e o próximo passo é iniciar o estágio 4, que é a Passagem definitiva do bastão para o sucessor.

Destaca-se, também, que E5 e E7 frisaram não envolver assuntos familiares na organização e vice e versa, buscando preservar as relações. Esta separação de papéis é citada por Oliveira (2006), ao afirmar sobre a importância da definição do que é pertinente ao ambiente familiar, e o que é do ambiente empresarial, preservando as relações.

Dalla Costa (2007) explica que, no estágio 2, os filhos decidiram por trabalhar na empresa e cabe a eles demonstrar habilidades, enquanto que, no estágio 3, as duas gerações já atuam na empresa. Bornholdt (2005) salienta que, esta é a fase mais eficaz para dirigir a empresa familiar, pois há uma mistura de novo e velho, há muito debate na tomada de decisão e troca de experiências. $\mathrm{O}$ autor também destaca que, a presença de um executivo mais maduro, é essencial para manter a identidade da empresa e conter a ansiedade interna.

\subsection{Nova gestão futura}

Quando questionados se há uma visão de um futuro sucessor e várias gerações trabalhando na empresa, apenas E4 afirmou, com convicção, que vê uma continuidade nas outras gerações, visto que, atualmente, a administração já é conjunta e todo o processo sucessório está sendo documentado para futuras sucessões. Oliveira (2006) relata que, o ciclo de vida médio das empresas familiares é de nove anos, sendo que, apenas uma pequena parcela sobrevive à segunda geração. $\mathrm{O}$ autor ainda apresenta que, $75 \%$ das empresas nos países industrializados, são de cunho familiar. Observa-se que todas as empresas participantes já ultrapassaram esta média de idade relatada, porém não há como garantir sua sobrevivência no mercado.

E1 não acredita na continuação da organização, e E2, E7, E3 e E6 acreditam que, a primeira geração (filhos) dará continuidade à empresa, pois já está esboçada esta sucessão e eles se preparam para isto, porém, ainda não acreditam em uma continuação após estes. O entrevistado E5 não possui uma visão de futuras gerações envolvidas na empresa até o momento, porque ainda não tem um sucessor definido, mas trabalha, constantemente, para melhorar processos internos e desenvolvimento de pessoas.

Tondo (2008) explica que, é difícil para o fundador se imaginar fora da empresa a qual ele deu a vida e fez crescer; para os funcionários de longa data, esta troca de gerência também é difícil, e, neste processo, o fundador torna-se o professor. Dessa forma, entende-se que, a falta de visualização das empresas em um futuro distante, pode ser explicada pela resistência que o fundador tem em se desligar da empresa a qual se dedicou durante longos anos.

Referente à perspectiva de crescimento da empresa com a gestão futura, todas as empresas afirmam visualizar um crescimento. Os entrevistados E1, E2, E3 e E7 tem perspectivas de expansão para a próxima geração (filhos). E6 
afirma já ter um plano de crescimento para o sucessor, e E5 também afirma ter perspectiva de crescimento, por estar desenvolvendo melhorias administrativas e produtivas, buscando certa consolidação empresarial. E4 não possui perspectiva de crescimento para esta geração, visto que, isso já está sendo feito no presente, com a administração conjunta do fundador e seus sucessores (pai e filhos). O que prospectam no momento para a futura gestão, é se compensa investir e crescer mais ou, manter o tamanho atual da organização.

Em relação ao desenvolvimento da organização, todas as empresas, com exceção da E4, estão no estágio de Expansão que, conforme Dalla Costa (2007), pode ser a fase mais extensa, podendo ultrapassar uma geração, onde a empresa busca estabilidade, criatividade e crescimento. Não há como garantir um futuro próspero para as indústrias familiares, porém, há meios de facilitar a sucessão. Neste sentido, Dalla Costa (2007) atenta para o cuidado que o sucessor deve ter ao gerir: ele não deve ser exatamente igual ao seu sucedido, ao mesmo tempo que não deve modificar tudo; o sucessor deve se ater a manter a sequência, preservando o que é bom e desenvolver o resto.

\subsection{Preparação do sucessor}

Sobre a existência de uma preparação para os possíveis futuros gestores, os entrevistados E1, E2 e E7 afirmam haver uma preparação para o futuro gestor através de cursos específicos na área e atividades no dia a dia, orientadas pelo sucedido. Observou-se ainda que, ambos os futuros sucessores, iniciaram suas atividades na produção, com exceção da E7, onde o sucessor já iniciou no administrativo e já é formado em Administração. E3, E5 e E6 afirmam não ter uma preparação específica para a sucessão, porém, o treinamento é diário, com base na experiência passada pelo sucedido e em atividades do cotidiano, envolvendo não somente atividades administrativas, mas também conhecimento de produção.

E4 possui uma preparação mais definida, onde os sucessores iniciaram na produção, e atuaram seis meses em cada setor antes de entrarem no departamento administrativo da empresa. Enquanto na produção, o fundador exigiu que cada um desenvolvesse uma melhoria interna no setor. Quando concluída a atividade, passavam para o próximo setor. Segundo o fundador da E4, esta foi a forma mais eficaz de transmitir um conhecimento geral da organização como um todo para os sucessores.

Este método utilizado pelo fundador da E4 é muito similar ao citado por Oliveira (2006), que sugere a prolongação do treinamento do sucessor escolhido, fazê-lo trabalhar em todas as áreas da empresa, inclusive nas de baixo nível hierárquico. Desta forma, ele aumentará seu conhecimento do negócio. Oliveira (2006) cita este método como uma ideia para amenizar conflitos de disputa de poder. Este não é o caso da E4, porém o método é de grande valia para ampliação de conhecimentos. Conforme já mencionado anteriormente, Tondo 
(2008) explica que, a preparação do herdeiro acontece no dia a dia, sendo esta a forma mais citada pelos entrevistados, através da experiência compartilhada, seguida de conhecimento técnico, conforme os relatos de E2 e E4 na sequência:

No início eu fui ensinando na parte da embalagem, depois massas para biscoito e depois ela foi para o escritório, ensinei fazer nota a mão e agora ela que faz tudo no computador. (E2)

Eles fazem alguns cursos técnicos. Estão fazendo, meus dois filhos, mas a preparação maior é no dia a dia aqui comigo. (E4)

E4, por ser uma empresa bem estrutura e de médio porte, possui algumas vantagens na sucessão familiar. Leone (2005) cita, como um ponto facilitador do processo, o fato de empresas deste porte possuírem mais capital e haver mais profissionais especializados contratados já atuando na organização. O que confere com a situação da E4, visto ser uma empresa bem estrutura, com grande capital humano qualificado.

\subsection{Planejamento a longo prazo}

Acerca da existência de um planejamento a longo prazo para o futuro gestor, os respondentes E1 e E7 explicam que há um planejamento para os próximos passos, onde o sucessor é muito participativo e interessado. Já E2 e E3 dizem não ter um planejamento de longo prazo para o futuro gestor, relatando que, conforme o surgimento dos problemas, toma-se a decisão no momento ou em curto prazo, período inferior a um ano.

O gestor da E4 já possui a administração de forma conjunta entre sucessores e sucedido, onde, de tempos em tempos, os sucessores trocam de funções entre eles para que um não fique totalmente dependente do outro. Para o futuro, o gestor imagina a continuidade do trabalho que já vem sendo desenvolvido e explica que os sucessores já têm condições, no presente, de assumir a direção total da empresa.

E5 não possui um planejamento para o futuro gestor, mas trabalha de forma organizada, com linha de produtos definida e processos claros e descritos. Acredita que isso facilita a compreensão do futuro gestor, e o processo de sucessão como um todo. Enquanto que, E6, planeja concluir a sucessão total para o herdeiro, porém, não possui nada documentado. Estas informações vão ao encontro das afirmações de Leone (2005) ao considerar que, o empresário brasileiro, em geral, não se preocupa muito com o planejamento, onde o processo de sucessão deve ser conduzido pelo sucedido. Adachi (2006) afirma que, o processo de sucessão é de responsabilidade do fundador, justamente, por exigir que se tenha um conhecimento pleno de todo histórico empresarial e familiar. 
Em relação à preparação do gestor para o cargo, e se ele já tem conhecimento da responsabilidade de dar continuidade à organização, os entrevistados E1, E2, E3, E6 e E7 dizem que sim, que o sucessor tem conhecimento e está se preparando de forma adequada, através da experiência diária, cursos sobre administração e cursos específicos de cada área respectivamente.

E4 explica que, os sucessores vêm se preparando para assumir a administração total da empresa há bastante tempo, e que, esporadicamente, o fundador desliga-se da empresa por alguns dias, deixando o comando para os sucessores, sem avisá-los previamente, testando as habilidades dos sucedidos, conforme relato a seguir:

Os dois estão sendo preparados para a sucessão, hoje se acontecer alguma coisa comigo eles tocam a fábrica, talvez não tocariam em primeira mão assim sabe, mas eles tocam, do jeito deles mas tocam, porque eles têm o conhecimento.

E5 não possui um sucessor definido no momento, e o fundador explica que, estão trabalhando para identificar e formar o sucessor, pensando, inclusive, em um plano $B$, caso esta pessoa não possa assumir ou não tenha as características necessárias. Esta situação descrita pela E5 vai ao encontro de outra possibilidade de sucessão, além da estritamente familiar, que é a sucessão profissional. Oliveira (2006) explica que, este tipo de sucessão pode ser uma solução, onde a empresa familiar busca um profissional contratado para gerir o negócio da família.

\subsection{Um novo líder em formação}

Sobre a receptividade do futuro gestor na organização, E1, E2, E3 e E7 afirmam que os demais funcionários sabem da sucessão e o respeitam da mesma forma que o sucedido, solucionando dúvidas e problemas, diretamente, com o sucessor. $\mathrm{O}$ entrevistado $\mathrm{E} 3$ revela, também, que na parte administrativa da empresa, quase todas as decisões são tomadas pelo sucessor, com sua supervisão. Já no setor produtivo, a gerência continua com o atual gestor. Esta aceitação por parte dos demais funcionários, não deve ser algo imposto, mas sim conquistado pelo sucessor. Tondo (2008) explica que à medida que o sucessor demonstra seu conhecimento, empenho, habilidades e atitudes, vai sendo reconhecido como adulto e profissional competente por parte dos funcionários mais antigos.

Os entrevistados E4 e E6 possuem uma boa receptividade dos funcionários com o sucessor, respeitando-o como pessoa e como futuro gestor, até pelo motivo de que, os sucessores destas duas empresas, já foram definidos há mais tempo, não sendo uma novidade para a organização. E5 relata que, os demais funcionários da organização, têm conhecimento parcial do possível futuro gestor, ao mesmo tempo em que sabem, também, que qualquer um, 
desde que tenha conhecimento técnico e esteja preparado para gerir, pode assumir o cargo.

A abertura desta possibilidade, de um gestor não herdeiro assumir a direção, demonstra que E5 ainda está avaliando o perfil deste possível gestor, procurando realizar uma avaliação profissional, o que atesta as afirmações de Oliveira (2006), onde o autor defende que, a questão da sucessão deve ser pensada desde o nascimento dos filhos, assim a análise do herdeiro e sua vocação profissional serão realizadas desde cedo, de forma gradativa, possibilitando a identificação de um sucessor ou não.

Das características de liderança requeridas para os futuros gestores, todos os entrevistados destacaram características importantes. A maioria dos sucedidos citou a postura do sucessor como uma característica de liderança (E1, E2, E3, E4 e E7). Pelo conteúdo das entrevistas, entende-se por "postura" ser um gestor formador de opinião, que toma decisões quando necessário e assume responsabilidades. Percebe-se que, as características citadas, são referentes à personalidade, vivência e experiência do sucedido e do sucessor, o que confere com Bornholdt (2005) e Oliveira (2006), visto que, os autores enfatizam não haver como herdar a capacidade de liderar, porém, há como exercitá-la. Este processo pode ser efetivado através de atitudes, como propor melhorias, solucionar problemas, criar canais de comunicação, interagir com os demais funcionários, entre outras atividades do cotidiano de uma empresa.

\section{CONSIDERAÇÕES FINAIS}

Esta pesquisa buscou verificar como os atuais gestores das indústrias familiares desse município planejam a sucessão de seus negócios para os sucessores. Através dos resultados obtidos, verificou-se que, a maioria dos gestores, embora tenha um planejamento, este ainda é informal e não documentado (dos sete gestores entrevistados, apenas dois possuem um planejamento formalizado em partes), evidenciando que o planejamento é algo adiado e não muito discutido na organização, podendo criar um clima de incerteza e até uma preparação inadequada do sucessor. Em casos mais extremos, uma sucessão mal conduzida pode ocasionar, até mesmo, o encerramento das atividades da empresa.

Observou-se, também, que a idade das empresas parece não influenciar no planejamento da sucessão, visto que, as duas empresas cujas já passaram por um processo sucessório, são as mais antigas: E3 com 45 anos, e Em6, com 78 anos. Apesar de já terem enfrentado a sucessão, nenhuma delas documentou o processo.

Dos gestores participantes, cinco estão no estágio de Entrada na empresa e Trabalho em conjunto com o sucessor. Contudo, percebe-se que não há uma preocupação por parte destes diretores em formalizar o processo de sucessão, ou torná-lo mais consistente e aplicável. Essa falta de planejamento formalizado, 
ou pelo menos um esboço de procedimentos para completar a sucessão, pode indicar que os diretores das empresas não têm uma perspectiva de outras gerações gerindo os negócios, confirmando dados anteriores, referentes à baixa expectativa de vida das empresas familiares, das quais, poucas ultrapassam a segunda geração. Essa falta de visualização de futuro pode ser atribuída à resistência que o diretor tem em debater, planejar e iniciar o processo de sucessão.

Constatou-se ainda que, as características consideradas essenciais para o sucedido das empresas analisadas, foram voltadas à personalidade e ao caráter do sucessor, as quais vêm se desenvolvendo com o tempo e com a experiência, não somente na organização, mas, também, no cotidiano do sucessor, por meio de pequenas tarefas diárias e do envolvimento na discussão de problemas e tomada de decisão. Todos os diretores, com exceção do E7, afirmaram que, o sucessor ou possível sucessor, iniciou suas atividades na linha de produção, reforçando o fato de que, as competências que os diretores mais valorizam, não são somente a formação acadêmica do sucessor, mas sim, os valores e princípios que ele carrega, a identidade a ser transmitida para a organização no futuro, e a sua postura perante os problemas gerenciais.

Por fim, ficou evidenciado que, os atuais gestores das indústrias familiares de Muçum/RS participantes deste estudo, em sua maioria, planejam a sucessão familiar, porém este processo é informal, intricado e não documentado, deixando que ocorra de forma natural e dentro das condições existentes, preparando o herdeiro por meio de sua experiência adquirida dentro da organização.

Embora esta pesquisa tenha alcançado seu objetivo, ressalta-se a existência de limitações, como a impossibilidade de generalizar resultados obtidos, uma vez que, estes são válidos somente para as empresas analisadas, pois cada organização possui características únicas e métodos de trabalho diferentes. Desta forma, buscando contribuir com as discussões acerca do processo de sucessão nas indústrias familiares, sugere-se uma pesquisa quantitativa, por meio da aplicação de questionários, com um maior número de participantes, tornando possível quantificar os resultados e realizar algumas generalizações. Além disso, também seria interessante pesquisar as expectativas dos sucessores destas empresas.

\section{REFERÊNCIAS}

ADACHI, Pedro Podboi. Família S.A: gestão de empresa familiar e solução de conflitos. São Paulo: Atlas, 2006.

BARDIN, L. Análise de conteúdo. 1. ed. 2. reimpr. São Paulo: Edições 70, 2011.

BELL, Judith. Projeto de pesquisa: guia para pesquisadores iniciantes em educação, saúde e ciências sociais. 4 ed. Porto Alegre: Artmed, 2008. 
BORNHOLDT, Werner. Governança na empresa familiar: implementação e prática. 1. ed. Porto Alegre: Bookman, 2005.

BRASIL. Lei complementar $\mathrm{n}^{\circ} 123$, de 14 de dezembro de 2006. Disponível em: <http://www.planalto.gov.br/ccivil_03/leis/LCP/Lcp123.htm>. Acesso: 15 set. 2017.

BRASIL. Lei complementar $\mathrm{n}^{\circ} 128$, de 19 de dezembro de 2008. Disponível em: <http://www.planalto.gov.br/ccivil_03/leis/LCP/Lcp128.htm>. Acesso: 15 set. 2017.

CRESWELL, John W. Projeto de pesquisa: métodos qualitativo, quantitativo e misto. 3. ed. Porto Alegre: Artmed, 2010.

DALLA COSTA, Armando. Sucessão e sucesso nas empresas familiares. 1. ed. Curitiba: Juruá, 2006, 2 reimpr. Curitiba: Juruá, 2007.

GIL, A. C. Como elaborar projetos de pesquisa. 3. ed. São Paulo: Atlas, 1996.

IBGE - Instituto Brasileiro de Geografia e estatística. Rio Grande do Sul, Muçum, 2010. Disponível em: <http:/ / cidades.ibge.gov.br/xtras/perfil.php?lang=\&codmun =431260\&search=rio-grande-do-sul $\mathrm{I}$ mucum $>$. Acesso em: 22 set. 2017 .

LEONE, N. M. C. P. G. Sucessão na empresa familiar: preparando as mudanças para garantir sobrevivência no mercado globalizado. São Paulo: Altas, 2005.

LODI, João Bosco. A empresa familiar. 5. ed. São Paulo: Pioneira, 1998.

OLIVEIRA, Djalma de Pinho Rebouças. Empresa familiar: como fortalecer o empreendimento e otimizar o processo sucessório. 2.ed. São Paulo: Atlas, 2006.

OLIVEIRA, S. L. Tratado de metodologia científica: projetos de pesquisa, TGI, TCC, monografias, dissertações e teses. 1.ed. São Paulo: Pioneira, 1997.

SAMPIERI, Roberto Hernández; COLLADO, Carlos Fernández. LUCIO, María Del Pilar Baptista. Metodologia de pesquisa. 5. ed. Porto Alegre: Penso, 2013.

TONDO, Cláudia. Desenvolvendo a empresa familiar e a família empresária. Porto Alegre: Sulina, 2008. 